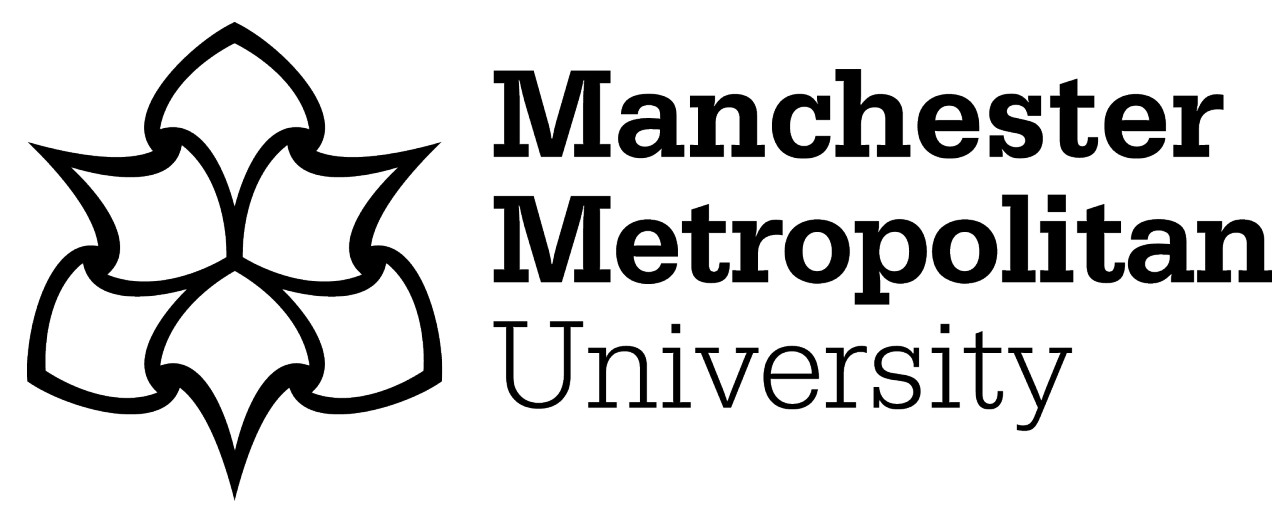

Omidvar, O and Kislov, R ORCID logoORCID: https://orcid.org/0000-00032525-7673 (2016) R\&D consortia as boundary organisations: Misalignment and asymmetry of boundary management. International Journal of Innovation Management, 20 (2). ISSN 1363-9196

Downloaded from: https://e-space.mmu.ac.uk/624109/

Version: Accepted Version

Publisher: World Scientific Publishing

DOI: https://doi.org/10.1142/S1363919616500304

Please cite the published version 


\title{
R\&D consortia as boundary organisations: Misalignment and asymmetry of boundary management
}

\author{
OMID OMIDVAR \\ Coventry University Business School \\ Coventry University \\ Priory St, Coventry CV1 5FB, United Kingdom \\ omid.omidvar@coventry.ac.uk \\ ROMAN KISLOV \\ Manchester Business School, University of Manchester \\ Oxford Rd, Manchester M13 9PL, United Kingdom \\ roman.kislov@mbs.ac.uk
}

\begin{abstract}
The article presents a qualitative multiple case study of three multilateral publicprivate $\mathrm{R} \& \mathrm{D}$ consortia representing different industrial sectors. Using the practice-based view as a theoretical lens, we explore the interplay between the deliberate and emergent practices of boundary management across the following three dimensions: (1) boundary bridging focus; (2) boundary crossing arrangements; and (3) collaborative governance arrangements. Drawing on interviews, documentary analysis and observational data, we describe the misalignment between the deliberate and emergent aspects of boundary management, which can be caused by the funders' reporting requirements, power differentials between collaborators and lack of contextual understanding. These factors, accompanied by path-dependency and confidentiality issues, may result in asymmetrical boundary management, whereby a selective focus on a specific boundary (or set of boundaries) combined with an unequal development of boundary bridges within the collaboration may lead to the crossing of some boundaries being prioritised at the expense of others.
\end{abstract}

Keywords: R\&D consortia; boundaries; boundary organisations; boundary management; boundary organising; practice-based view; strategy; collaboration

Electronic version of an article published online before print at International Journal of Innovation Management [DOI: 10.1142/S1363919616500304]

(C) [copyright World Scientific Publishing Company]

http://www.worldscientific.com/doi/abs/10.1142/S1363919616500304?src=recsys 


\section{Introduction}

With the recent move towards open innovation, R\&D collaborations and other approaches to sourcing external knowledge through inter-organisational networks have become increasingly widespread in innovative industries (Chesbrough, 2003; Perkmann and Walsh, 2007; Howells, 2008; Chesbrough, 2011). Previous research suggests that the expected innovation advantages of research collaborations can be outweighed by managerial hurdles created by complexity, governance costs, knowledge stickiness and lack of control (Bidault and Cummings, 1994; Mohr and Spekman, 1994; Dyer and Song, 1998; Becker and Dietz, 2004; Bogers, 2011). These issues are particularly prominent in multilateral $R \& D$ consortia comprising multiple partners with diverse institutional interests, occupational practices and operating principles (Oxley and Sampson, 2004; Li et al., 2012). Such consortia therefore have to play the role of boundary organisations, i.e. entities that serve the interests of multiple partners and mediate complex boundary negotiations as part of their routine work (Guston, 1999, 2001; Mørk et al., 2008; Mørk et al., 2012).

Dealing with multiple boundaries has long been seen as an important part of successful R\&D management (Organ and Greene, 1972), with a growing understanding that boundary processes are complex, evolving and contingent on multiple macro- and micro-level factors (Cilliers, 2001; Barrett et al., 2012; Mørk et al., 2012). Responding to the calls to combine macro- and micro-levels of theorising innovation (Crossan and Apaydin, 2010; Bromiley and Rau, 2014), we adopt the practice-based view to analyse the strategies of boundary management in multilateral R\&D consortia. Reflecting on the interplay between 'espoused' and 'actual' practices (Mintzberg and Waters, 1985; Brown and Duguid, 1991; Whittington, 2006; Crossan and Apaydin, 2010), we explore how boundary management decisions intentionally made as part of a planned strategy 
(the deliberate aspects of boundary management) are transformed in the process of implementation through the actual boundary reconfigurations at the level of practice (the emergent aspects of boundary management). We aim to address the following research questions. What forms does the interplay of deliberate and emergent boundary management practices take in a complex boundary organisation and why? What are the implications of this interplay for multiple boundaries contained within a boundary organisation?

By presenting a multiple case study conducted in three inter-organisational $\mathrm{R} \& \mathrm{D}$ consortia, we discuss the interplay between the deliberate and emergent practices of boundary management across the following three dimensions: (1) boundary bridging focus; (2) boundary crossing arrangements; and (3) collaborative governance arrangements. Our theoretical contribution is twofold. First, we explore the mechanisms and consequences of misalignment between the deliberate and emergent practices of boundary management. Second, by looking at an inter-organisational collaborative enterprise as a complex system of overlapping boundaries, we describe the inherent asymmetries of boundary management that are apparent in the prioritisation of certain boundaries and marginalisation of others, in the unequal distribution of boundary spanners across the system, and in the influence of the more powerful members of the collaboration on destabilising and restabilising boundaries. The findings of this study are applicable to a wide range of $\mathrm{R} \& \mathrm{D}$ collaborations and other boundary organisations, such as scientific advisory agencies, technology transfer offices and knowledge transfer organisations.

The next section provides a theoretical background of the study, using the practice-based view of strategy to crystallise our theoretical argument, identify 
knowledge gaps and formulate research questions. The third section describes the three R\&D consortia selected for empirical investigation and outlines the procedures for data collection and analysis. The fourth section explores the main findings of the study, focusing on the interplay between the deliberate and emergent aspects of boundary management. The fifth section discusses the findings of the study in light of existing literature, introduces the notions of misalignment and asymmetry in boundary organisations and explores practical implications for handling multiple boundaries in R\&D collaborations. This is followed by a brief concluding section outlining the contribution of the study, its limitations and implications for future research.

\section{Theoretical background}

\section{1. $R \& D$ consortia as complex boundary organisations}

Organising the ecologies of complex innovation is a challenge due to the presence of multiple organisations with diverse institutional interests, occupational practices, and operating principles (Dougherty and Dunne, 2011). This diversity, in turn, generates multiple boundaries, broadly defined as sociocultural differences between organisations and groups that can potentially lead to discontinuity in action or interaction, retarding the spread of innovation (Ferlie et al., 2005; Akkerman and Bakker, 2011). Publicprivate $\mathrm{R} \& \mathrm{D}$ consortia can be conceptualised as boundary organisations because they involve the participation of actors from relatively distinct social worlds, such as science, policy and industry; have definite lines of accountability and responsibility to each of them; and provide a space for the creation of commercial innovation at the interface of multiple boundaries (Guston, 1999, 2001). 
With the number of partners, the number of multilateral relationships that an $R \& D$ consortium has to balance increases (Morris, 2003; Slipersæter et al., 2007; Klerkx and Leeuwis, 2008). Multilateral R\&D consortia can therefore be expected to demonstrate a number of characteristics of complex systems, such as the presence of interdependent parts and multiple boundaries (organisational, professional and departmental), a move from command-and-control styles of management towards self-organisation and a propensity to evolve over time (Anderson, 1999; Cilliers, 2001; Burnes, 2005). Another key characteristic of boundary organisations is their ability to effectively operate in multiple arenas, mediate negotiations across the boundaries as part of their routine work and deal with all parties to which a boundary organisation is accountable (Guston, 1999, 2001; Klerkx and Leeuwis, 2008).

To unpack the complex and evolving nature of boundary processes, this paper adopts the practice-based view on the strategies of boundary management in multilateral $R \& D$ consortia, whereby 'strategy is more than just a property of organizations; it is something that people do' (Whittington, 2006, p. 627). This approach highlights the dual nature of boundaries which can function both as sites of knowledge creation and as 'barriers' or 'gaps' stifling innovation and decreasing organisational performance (Wenger, 1998; Dougherty, 2004; Kislov, 2014). Boundary management therefore involves a set of activities aiming to enhance the positive and overcome the negative effects of boundaries. Applying the practice-based approach to its analysis would imply the integration of the micro- and macro-levels of theorising by exploring the activities that individual actors conduct in relation to boundaries (i.e. boundary management practices), the organisational effects of these activities (both positive and negative), and the organisational and institutional factors that influence 
their implementation and outcomes (Crossan and Apaydin, 2010; Bromiley and Rau, 2014). These aspects are discussed in more detail in the next two subsections.

\subsection{Deliberate and emergent strategies of boundary management}

When approaching the strategic practices of boundary management as an 'empirical object' (Corradi et al., 2010, p. 268) it is important to distinguish between the following two diverging dimensions. The first dimension includes deliberate strategic practices that are planned in advance and subsequently realised as initially intended. Reflecting the 'espoused' practices of an organisation (Brown and Duguid, 1991; p.41), these are underpinned by organisation- or sector-specific cultures, norms and procedures and are often made explicit in the form of written policies and plans. The second dimension is represented by emergent strategic practices, denoting the 'actual' practices which are realised despite, or in the absence of, intentions. Rather than originating from formal plans, central vision or shared beliefs, these practices are embedded in the everyday routine of actors in a context shaped by internal sense-making, politics and communication structures as well as by external environmental constraints. Over time, however, emergent strategic practices may become institutionalised, thus giving rise to deliberate practices (Mintzberg and Waters, 1985; Brown and Duguid, 1991; Whittington, 2006).

Previous research into the deliberate strategies of boundary management emphasises the importance of organisational design, boundary 'bridges', and shared spaces for negotiating meanings and developing new cross-boundary practices in complex boundary organisations (Kislov, 2014). Dodgson (1992) suggests that managing an R\&D collaboration should be a strategic concern and highlights the importance of selecting appropriate partners, developing adaptable and flexible structures, and 
building effective communication paths. Based on their study of technology transfer offices in public-private research collaborations, Shohet and Prevezer (1996) emphasise the importance of intermediaries in managing contractual, financial linkages that accompany knowledge flows between research sponsors, hosts and users. Finally, Roelofsen et al. (2011) argue that a carefully structured dialogue method aligning the interests of the demand side with those of the supply side is critical for crossing the boundaries in innovation networks.

A number of recent empirical studies have looked at emergent boundary processes, where the relationships between various boundaries are affected by the changes in joint working practices across multiple organisational or occupational groups induced by a technological innovation, policy imperative or organisational restructuring. This research emphasises the emergent, context-dependent and adaptive nature of boundary management (O'Mahony and Bechky, 2008; Barrett et al., 2012; Hsiao et al., 2012; Evans and Scarbrough, 2014). For instance, exploring the encounter of various occupational groups within an innovation research project, Mørk and colleagues (2012) identify handling multiple boundaries, facilitating mutual benefit and mutual adaptation of practice as key components of successful 'boundary organising'. The latter can be seen as a relational process of destabilising boundaries to include new actors and resources, followed by boundary restabilisation which stabilises the modified practice and protects it from external actors with conflicting interests.

\subsection{Factors affecting the processes and outcomes of boundary management}

Boundary management can be challenging in complex boundary organisations comprising multiple groups. It is likely to be shaped by the properties of a boundary, the characteristics of partners and the factors of a broader organisational and institutional 
context. Boundaries underpinned by strong identity differences, markedly divergent meanings and intensive power struggles are more difficult to manage than others (Carlile, 2004; Akkerman and Bakker, 2011; Kislov et al., 2012; Kislov, 2014). An organisation's size also matters: there are usually fewer boundaries in smaller firms (Gulati et al., 2009; Kislov et al., 2012). As far as external context is concerned, it can be assumed that it is easier to manage boundaries in $R \& D$ consortia operating in industries with weak competition and appropriability regimes (Sakakibara, 2002).

Recurrent cooperation with the same partners (partner-specific experience) generates trust, decreases information asymmetry and increases the relative efficiency of learning, enabling the crossing of a boundary between R\&D partners ( $\mathrm{Li}$ et al., 2008; Gulati et al., 2009). On the other hand, there is empirical evidence suggesting that previous partner-specific experience may decrease alliance performance through organisational inertia, complacency and knowledge ossification (Hoang and Rothaermel, 2005). Path-dependent approaches to selecting the partners and, more broadly, to managing boundary relationships can be beneficial for incremental innovation but are less likely to result in radical innovation and transformation of the boundary (Rycroft and Kash, 2002; Li et al., 2008).

As the practice-based view is not confined to an analysis of practices improving performance (Bromiley and Rau, 2014), it is also important to consider unintended and potentially negative consequences of boundary management practices. Boundary reconfigurations in the process of joint working can include not only cooperation between groups on either side of the boundary, but also marginalisation of less powerful groups, unilateral loss of control and work fragmentation (Barrett et al., 2012). Kislov (2014) demonstrates that a collaborative research partnership created with an explicit 
purpose of bridging the boundaries between organisational and occupational groups can, paradoxically, reinforce old and create new boundaries through fragmented organisational design, the use of divergent meanings as mechanisms of boundary legitimation, and the rhetoric deployment and marginalisation of boundary bridges. Organisational restructuring that affects organisational, professional and group boundaries may increase boundary complexity and threaten identity, differentiation and interaction between different groups (Hyde, 2006).

\subsection{Knowledge gaps and research questions}

Based on the analysis of theoretical and empirical literature presented above, we argue that $\mathrm{R} \& \mathrm{D}$ consortia can be conceptualised as complex boundary organisations characterised by multiple boundaries; that managing these boundaries involves a range of deliberate and emergent strategic practices which are likely to diverge over time, occasionally leading to unintended consequences; and that the interplay between these two types of strategic practice is shaped by a combination of intra-organisational and extra-organisational factors.

At the same time, our knowledge about boundary management in R\&D consortia and other complex boundary organisations is still limited in a number of ways. First, previous literature has largely focused on the role that a boundary organisation plays in aligning actors' interests across boundaries, without adequately reflecting the complexity of boundary organisation and the evolving nature of boundaries and boundary management. Second, the interplay between deliberate strategic attempts to manage boundaries in the process of $R \& D$ collaboration and emergent practices of boundary management has received little empirical attention. Finally, whilst 'in practice the boundary continues to be negotiated at the lowest level and the greatest nuance 
within the confines of the organization' (Guston, 2001, p. 401), the differential effects of deliberate and emergent boundary management practices on multiple boundaries within a complex boundary organisation remain underresearched.

This study aims to address these gaps by exploring how the deliberate aspects of a boundary management strategy deployed by the leadership of a collaborative enterprise become entangled with the emergent boundary organising practices developing at the local level. It is guided by the following research questions. What forms does the interplay of deliberate and emergent boundary management practices take in a complex boundary organisation and why? What are the implications of this interplay for multiple boundaries contained within a boundary organisation?

\section{Methodology}

This article is based on three case studies of inter-organisational R\&D collaborations (anonymised here as HOUSE, ASTHMA and FLIGHT—see Table 1) that were selected based on the following criteria: (1) the representation of different industrial sectors; (2) the presence of several types of boundaries in each collaboration (e.g. sectoral, organisational and disciplinary); (3) a relatively high level of mutual engagement and interaction between the collaborators. These criteria led to the identification of a pool of R\&D consortia that could potentially be selected as our final cases. However, the final selection of cases was further limited by the level of access that we were granted. This meant that we had to exclude (1) a number of $R \& D$ consortia that did not give access to us and (2) those which only agreed to give limited access. In fact, we had to drop the fourth case after we conducted a number of interviews because the level of access the organisation was prepared to grant was insufficient for an in-depth exploration of boundary management. 


\section{Insert Table 1 about here}

We conducted 47 interviews (45-90 minutes in duration) with 42 research participants representing various organisations and disciplines across the three cases (See Tables 1 and 2), with some of the key informants interviewed twice. The overall approach was to interview all the individuals participating in the consortia. However, at times, compromises had to be made because a few participants did not want to be interviewed or had left their organisation since the completion of the project. In the latter case, we managed to interview some at home, or at their new workplace. This strategy worked for most of the participants, but there were still a relatively minor number of participants whom we could not reach. However, all of the key informants in each consortium were interviewed as planned.

All interviews were recorded and transcribed verbatim and the transcripts were sent back to the interviewees for validation. Semi-structured interviewing was supplemented by the analysis of documents including the quarterly and annual reports, project completion reports, exploitation reports, quarterly presentations, patent applications and meeting minutes. The HOUSE and FLIGHT projects had been completed when we started gathering field data, whereas ASTHMA was in the middle of its life cycle, so it was possible to obtain observational data from ASTHMA. One of the authors attended a three-day annual ASTHMA conference which provided ample opportunities for informal talks with the participants. Triangulation of data obtained by different methods (Table 2) helped with minimising bias, achieving synergy in data and eliminating inconsistencies (Eisenhardt, 1989; Yin, 2009).

Insert Table 2 about here 
In the first stage of data analysis, a description of the cases was developed which covered the main events, changes and problems, particularly exploring the narratives around discontinuities throughout the collaborations. The main purpose of this stage was to create a consistent narrative in which the facts gathered from the case converge to form conclusions from the same case (Langley, 1999). The second stage of data analysis involved developing a more analytical account of the findings by iterative comparing and contrasting them with the theories developed in the literature. As a result of this, we developed the first-order themes which presented the deliberate and emergent aspects of boundary management (boundary bridging focus; boundary crossing arrangements; collaborative governance arrangements). These themes were extensively discussed between the authors to ensure their validity. Matrix analysis (Miles and Huberman, 1994; Nadin and Cassell, 2004) was utilised to explore the similarities and differences between the three cases as well as the distinctions between the deliberate and emergent aspects of boundary management. To remain systematic, we used NVivo 8 software for coding and retrieval of data.

\section{Findings}

All of the three analysed cases demonstrate remarkable differences between the ways through which boundaries are designed to be encountered, bridged and governed, and the ways these aspects emerge throughout the collaboration process (Table 3). In what follows, we explain each of the three main aspects of boundary management in detail.

Insert Table 3 about here 


\subsection{Boundary bridging focus}

\subsubsection{Deliberate aspects}

In all three cases, inter-organisational boundaries between public and private partners received the highest attention at the design stage, which could often be explained by the explicit remit of the funders in facilitating public-private $R \& D$ collaboration. The HOUSE and the FLIGHT projects were co-funded by UK Technology Strategy Board (TSB) — a public agency for facilitating business innovation. ASTHMA was part of the Innovative Medicine Initiative (IMI) - a large European initiative aiming to accelerate the translational process of drug discovery from lab to patients. All of the three R\&D consortia focused on bridging the boundaries between public organisations (universities and research institutes) and private companies (SMEs, large companies and start-ups) since the allocation of funding depended on the participation of both public and private organisations in $\mathrm{R} \& \mathrm{D}$ collaboration. Research proposals and project documents highlighted the central role that was assigned to crossing public-private boundaries and fostering academic-industry engagement.

\subsubsection{Emergent aspects}

In addition to inter-organisational boundaries between public and private partners described above, there were other boundaries which received less attention from the design point of view but had a significant impact on the internal dynamics of the R\&D collaborations. First, there were strong disciplinary boundaries that acted as a hurdle in communication between different occupational groups. For instance, in the ASTHMA case there was a considerable miscommunication and 'difference in the mindset' (medical academic, university) between systems biologists who were interested in large 
scale datasets, on the one hand, and biologists and medical doctors who mainly worked with data obtained from small-scale experiments, on the other.

Second, the collaborations involved inter-departmental boundaries which were underpinned by the lack of resources for developing cross-departmental communication, by the prioritisation of other projects unrelated to the consortium and by the confidentiality agreements preventing the spread of knowledge to those departments who were not formally part of the collaboration. In HOUSE and FLIGHT, particularly, the knowledge about the technologies being developed did not spread effortlessly beyond project teams and the R\&D departments involved. For instance, in FLIGHT the engineering department of the coating manufacturer did not participate in meetings because the engineering department was not officially part of the project. Their interactions with the consortium were mediated by the $R \& D$ department of the coating company, which delayed the production process.

Finally, there were some salient inter-organisational boundaries which had not been envisaged at the design stage. For instance, in the early stages of the ASTHMA collaboration there were strong boundaries between the private partners engaged in competitive pharmaceutical research. In FLIGHT, the boundary between the aircraft manufacturer and the other two partner organisations (the university and the airplane coating manufacturer) was problematic. Because of its size, highly routinised procedures, and specific safety requirements imposed by regulating bodies, the aircraft manufacturer was considerably different from the rest of the partners with regard to their attitudes towards research, experimenting, timing, quality and efficiency. At the same time, the boundaries between the university and the coating company were much easier to manage, which research participants explained by a previous history of 
institutional as well as personal ties, previous co-participation in $R \& D$ consortia, and being 'on the same page' (research scientist; coating manufacturer).

\subsection{Boundary spanning arrangements}

\subsubsection{Deliberate aspects}

Designed arrangements for boundary interactions included regular face-to-face meetings (held quarterly in HOUSE and FLIGHT and annually in ASTHMA), in which the partners presented project results and discussed technical and managerial problems where the project partners had the chance to report on their progress and discuss various challenges. As for the digital communication, ASTHMA used an online system as a platform for communications, storing meeting minutes, and viewing milestones. In addition, a research tool for aggregating and analysing large-scale patient data was deliberately used to enable collaboration between systems biologists, statisticians, biologists and clinicians. Interestingly, no formalised knowledge brokering roles were created to bridge the boundaries between partners in any of the three cases.

\subsubsection{Emergent aspects}

First, knowledge brokers emerged during the collaboration, but their roles varied across the cases. In HOUSE, a postdoctoral researcher acted as a bridge between the university and the industry partners by supplying experimental data, arranging ad hoc meetings and providing coordination through emails and phone calls. An MPhil researcher, placed in a structural engineering company, was instrumental in explaining some of technical jargon to people from other organisations, but the student's lower status inevitably limited his knowledge brokering potential. In ASTHMA, despite the efforts to mobilise postdoctoral researchers across the collaboration (e.g. by placing them in pharmaceutical companies) in order to enable knowledge transfer between academic 
and industry partners, the majority of postdocs were involved in the collaboration on a part-time basis, kept changing throughout the lifecycle of the project and did not have a significant impact on bridging the boundaries. Finally, in FLIGHT, knowledge brokering between companies proved difficult due to confidentiality considerations.

Second, the meetings specified in the initially designed arrangements were complemented by the creation of additional boundary interactions or modification of the existing ones. For instance, structural engineers from different partner organisations involved in HOUSE started having separate meetings which helped bridge interorganisational boundaries. One of the important topics in these meetings was discussing the content and format of presentations at subsequent quarterly meetings attended by different occupational groups, for whom the technical complexity of the structural engineering jargon had to be simplified. In FLIGHT, boundary spanning was enhanced by rotating quarterly meetings between partners' sites. This helped the partners get an appreciation of each other's day-to-day practices, which significantly increased partners' understanding of each other's limitations.

Finally, in ASTHMA, public institutes emerged as sites for bridging boundaries between private companies when commercial knowledge could not be directly shared between competitors. For instance, when a particular viral technique was supposed to be transferred between two pharmaceutical companies, a researcher from a publicly funded research institute was temporarily placed in the first company to learn the technique. After the technique was adopted by the public research institute, a researcher from the second pharmaceutical company was placed in the institute to learn the same technique and bring it back to their organisation. Public research institutes also 
hosted the data generated by the private companies and facilitated their sharing among partners.

\subsection{Collaborative governance arrangements}

\subsubsection{Deliberate aspects}

All of the three collaborations were accountable to external funding bodies and followed formal contractual agreements. They had to develop a detailed project plan with deliverables and milestones, with project leaders held responsible for monitoring the overall progress of work. HOUSE and FLIGHT had a project monitoring officer who attended all meetings and reported the progress of the projects to TSB. In ASTHMA, there were annual progress reports which were submitted to IMI. However, some participants found the reporting routine (the requirement to report their findings and progress on a quarterly basis) 'time-consuming and sometimes irrelevant' (anonymised research participant, FLIGHT) as they had to engage in the formalities instead of actually working on the project. Finally, in terms of formal leadership, the design company was leading the collaboration in the HOUSE project; the coating manufacturer was the leading organisation in FLIGHT; and the ASTHMA project was formally led by one of the universities.

\subsubsection{Emergent aspects}

The formal governance structures described above were accompanied by emergent governance arrangements which developed differently across the cases but had a profound effect on the processes of boundary reconfigurations. In HOUSE, the three core partners (the university, the design company and the engineering company) shared de-facto leadership of the collaboration, which was enabled by a previous history of collaborative projects, regular institutional and individual interactions prior to this 
collaboration, and relatively insignificant disciplinary differences. Whilst positively contributing to development of shared understanding among the core partners, this arrangement, however, contributed to excluding other partner organisations from the decision-making process and resulted in one of the non-core partners leaving the consortium.

In ASTHMA, the academic leads from the universities had more control over the overall direction of the work because of their reputation, knowledge of the field and history of previous joint working. The fact that academic partners were mainly following their models and methodologies made it difficult to find a unified approach for conducting studies and comparing results. This, at times, was frustrating for industry partners who were keen to accelerate the process, complete the tasks according to deadlines, and deliver the project objectives. However, as they did not enjoy a similar level of power within the R\&D consortium, they had to be more 'tactful' (senior manager, pharmaceutical company) when interacting with academics.

In FLIGHT, the collaboration was dominated by the aircraft manufacturer which was a potential end-user of the product and was significantly larger than the other partners. They would closely monitor the performance of other collaborators and put pressure on the partners to comply with their requirements. This resulted in tensions as partners found themselves 'giving way' (research director, bearing company) to the aircraft manufacturer instead of engaging in a dialogue. This power imbalance further perpetuated the boundary between the aircraft manufacturer and the other three partners and resulted in asymmetrical boundary organising, where knowledge sharing was relatively unproblematic only between the coating company and the university, while 
the salient boundaries between the aircraft manufacturer and the other partners generated discontent, miscommunication and delivery delays.

\section{Discussion}

\subsection{Deliberate and emergent boundary management: Misalignment and}

\section{asymmetry}

Emergence of a complex overlapping system of boundaries-disciplinary, departmental and organisational-in R\&D consortia is not surprising (Dougherty and Dunne, 2011). What is surprising, however, is that few boundaries other than those between the private companies and public institutions were explicitly taken into account when these R\&D consortia were designed. The same applies to the deliberate boundary crossing arrangements, which were largely limited to face-to-face meetings, teleconferences and electronic communication systems, with no specific plans to create knowledge brokering roles or facilitate joint practices bringing together representation from different organisations and teams. Although $R \& D$ collaborations are seen in the literature as boundary organisations, with effective boundary crossing being an important prerequisite of successful innovation (Allen et al., 2007), our findings suggest that deliberate strategies of boundary management in $R \& D$ consortia may remain somewhat underdeveloped.

In each of the three cases, deliberate arrangements for boundary management were complemented by emergent mechanisms of boundary bridging. The latter included opportunistic development of knowledge brokering roles fulfilled by junior researchers; tailoring previously designed boundary interactions to local realities; creating new boundary interactions to help bridge emergent boundaries; and relying on public 
research institutions as intermediaries between private companies. These findings resonate with previous observations about emergent boundary spanners who may utilise their boundary position to become legitimate negotiators on behalf of their organisations (Levina and Vaast, 2005). It should be noted, however, that the effectiveness of junior researchers as knowledge brokers may be limited by their relatively low status in the local hierarchy (Fernandez and Gould, 1994; Currie and White, 2012).

Deliberate strategies of boundary management occasionally enabled opportunities for emergent boundary crossing (e.g. ad hoc on-site discussions while participating in quarterly meetings). However, they often failed to allocate sufficient attention and resources to the most problematic boundaries or to create a system of boundary crossing arrangements enabling knowledge transfer and lateral learning within the R\&D consortia. Moreover, informal leadership arrangements emerging within the consortia often directly contradicted formal governance structures specified in the organisational documents. Such misalignment can be explained by the reporting requirements of collaboration funders, strong power differentials, lack of contextual understanding of the collaborative enterprise and insufficient analysis of relevant boundaries at the start of the collaboration. Under these conditions, boundary organisations may still provide durable structures to reinforce mutual adaptation of collaborators (O'Mahony and Bechky, 2008) but, contrary to Mørk et al. (2012), such mutual adaptation is often achieved through accommodating the interests of the more powerful collaborators rather than through facilitating mutual benefit (cf. Oborn and Dawson, 2010).

These factors, accompanied by path-dependency and confidentiality issues, may also result in asymmetrical boundary management. In this case, focusing on a 
specific boundary (or set of boundaries) combined with an unequal development of boundary bridges within the collaboration (cf. Kislov, 2014) may lead to boundary crossing being prioritised at some boundaries at the expense of others. Our findings also highlight that in the absence of designed knowledge brokering roles, emergent knowledge brokers had different degrees of visibility across the cases and contributed to bridging of a limited number of boundaries. We thus further develop a theory of boundary reconfiguration in complex boundary systems (Barrett et al., 2012) by highlighting that not only occupational groups positioned at the boundary, but also boundaries and boundary bridges themselves can occasionally be neglected in the process of restabilisation, which can inevitably shift the strategic development of a boundary organisation as a whole. The HOUSE case also demonstrates that previous partner-specific experience, whilst enhancing the learning processes between the previously collaborating partners (Gulati et al., 2009), may contribute to the marginalisation of other partners in multilateral $R \& D$ collaborations.

As can be inferred from the above, the interplay of deliberate and emergent practices of boundary management can display variation across different R\&D consortia. Following the conventions of the practice-based approach, we placed the use of boundary management practices in the centre of our empirical exploration (Bromiley and Rau, 2014), identifying multiple macro- and micro-level factors that influence the selection, implementation and outcomes of these practices in specific contexts. Institutional constraints (e.g. funding arrangements, policy regulations and appropriability regimes), organisational factors (e.g. the size of the alliance and its constituent parts, availability of resources and history of collaboration) and intraorganisational characteristics (e.g. the degree of epistemic difference or the power status of a knowledge broker) are likely to differ across R\&D consortia, accounting for 
variation in the use of strategic practices of boundary management and their effects, both direct (such as the degree of boundary permeability and efficiency of knowledge transfer) and indirect (such as the consortium performance).

\subsection{Practical implications for $R \& D$ managers}

Since many strategies of boundary management emerge in reaction to the specific contexts within an R\&D consortium, it would be naïve to think that a successful boundary organisation, especially the one bringing together multiple partners, can be designed in the ready form prior to the start of the actual collaborative process. On the other hand, failing to envisage the emergence of boundaries or create conditions for the development of boundary crossing mechanisms could be detrimental for knowledge sharing and learning within a collaborative enterprise. The following subsection presents some practical recommendations for those managing collaborative R\&D projects and a wider range of multilateral boundary organisations. These recommendations are based on the premise that boundary management strategies should be actively utilised in the design of a collaborative enterprise whilst still allowing project-specific, context-tailored boundary management practices to emerge organically.

At the planning stage, the architecture of the R\&D collaboration should be analysed in relation to the salient boundaries that could emerge between and within organisations as well as between professional groups involved. Successful cooperation and crossing between some of the partners can be accompanied by 'strain' and 'neglect' at other boundaries (Barrett et al., 2012), and such boundary asymmetry should be counterbalanced. Aside from the boundaries between public and private organisations that are explicitly addressed by management of government-supported R\&D 
collaborations, the boundaries between private companies deserve special attention, especially in those cases where the boundaries are underpinned by IP and confidentiality arrangements, and/or where competition between some of the partners may be expected. In such cases using public partners, the collaboration's core management team or other groups as intermediaries may be considered as a potential solution.

In addition to intermediation at the organisational and group level (also see Howells, 2006), the creation of individual knowledge brokering roles with a specific remit in spanning organisational, disciplinary and departmental boundaries should be encouraged. When creating such roles, it is important to remember that knowledge brokers should be given sufficient resources and power to fulfil their functions successfully (Kislov, 2014); that they should be represented at different levels within the organisations (e.g. professional; middle-managerial; top-managerial) and distributed at multiple boundaries (Fitzgerald et al., 2013); and that knowledge brokerage is a group phenomenon requiring the involvement of teams and networks (Currie and White, 2012; Waring et al., 2013). As our example of junior post-doctoral researchers has shown, knowledge brokering functions can sometimes be performed by individuals whose formal duties do not necessarily involve brokerage; such cases should be identified and supported by the management of the collaborative enterprise.

Some of the arrangements for boundary crossing, such as meetings or reporting arrangements are in danger of becoming too formalised and far removed from the realities of actual boundary work. While it is hardly possible to minimise the amount of reporting in complex contractual settings such as $\mathrm{R} \& \mathrm{D}$ consortia, it is worth making sure that $R \& D$ managers use project reports and databases as 'facilitative boundary 
objects' (Fox, 2011) enhancing learning and knowledge sharing among the partner organisations and individual projects rather than 'ticking the boxes' (also see Swan et al., 2010). Delegations and site visits could be useful 'boundary encounters' (Wenger, 1998) complementing more traditional project meetings and enabling R\&D partners to have a glimpse into each other's practices.

Generating practice-based knowledge for managing boundaries can be enhanced by encouraging practitioners to interweave their 'designing' and 'using' practices (routinely considering the impact of design on implementation), participating in the whole flow of 'designing and using' (rather than focusing on a part of it) and reflecting on boundary management practices in action (articulating emergent practicesin-use) (Dougherty, 2004, p. 43). Learning to manage boundaries in R\&D alliances is vital for their performance and should receive no less attention than core capabilities traditionally associated with high competitive advantage and performance. It can be supported by using organisational channels of communication for sharing knowledge related to boundary management (Kislov et al., 2014) and encouraging individuals and teams involved in collaborative $R \& D$ projects to articulate how they have achieved their goals, not only what they have achieved, i.e. on procedural knowledge rather than product knowledge (Newell, 2004).

\section{Conclusion}

By discussing the interplay of the deliberate and emergent aspects of boundary management, we shift from previous research on established organisations where boundaries are relevant, clear and primarily under the control of management (Santos and Eisenhardt, 2005) towards exploring boundary phenomena arising in relatively nontraditional settings of cross-sectoral, inter-organisational and multidisciplinary R\&D 
collaboration. We show that there is a gap between the deliberate and emergent strategies of boundary management which can occasionally reach the level of misalignment, whereby deliberate boundary configurations and boundary crossing arrangements can, paradoxically, impede actual boundary crossing in practice. We also show that in complex multilateral boundary organisations, such as cross-sectoral R\&D collaborations, boundary management is at a risk of becoming asymmetrical, whereby some boundaries can become neglected, particularly due to power differentials, previous partner-specific experience and confidentiality issues.

This paper has predominantly dealt with misalignment between the deliberate and emergent aspects of boundary organising and asymmetry in the treatment of different boundaries by actors operating in inter-organisational collaborations, in which structures and processes often lie beyond the immediate control of members of the collaboration, and whose membership can be characterised as ambiguous, complex and dynamic (Huxham and Vangen, 2000a, 2000b). Lack of attention to alignment and symmetry is one of the limitations of the paper, while other limitations include relatively little observational data and a small sample size. Focusing on the practices of boundary management within individual $R \& D$ consortia yielded rich empirical data at the organisational level of analysis but meant less emphasis on external determinants of misalignment and asymmetry acting at the institutional level. We have also left out the discussion of innovation outputs as boundary objects helping to coordinate the process of boundary crossing in multiprofessional arena as this has been extensively discussed in extant organisation studies and knowledge management literatures (Carlile, 2002; Levina and Vaast, 2005; Oswick and Robertson, 2009; Kimble et al., 2010; Akkerman and Bakker, 2011; Fox, 2011; Hsiao et al., 2012). 
A successful boundary organisation should encompass more than the fulfilment of the vested interests of powerful actors and creation of formalised channels for knowledge transfer; it needs to combine a design incorporating the principles of lateral learning across multiple groups and organisations with the flexibility to enable the development of new boundary crossing practices as mandated by local contexts. Many questions, however, still remain unanswered. How are misalignment and asymmetry dealt with by highly successful boundary organisations? How does the orchestration of collective responsibilities (described in co-located communities of practice; see for example, Hsiao et al., 2012) unfold in inter-organisational contexts with substantial power differentials? How do the deliberate strategies of boundary management change in collaborative enterprises over time under the influence of emergent practices? These aspects could become fruitful lines of future inquiry.

\section{Acknowledgements}

We thank the two anonymous reviewers for their constructive comments on an earlier version of this paper. The first author acknowledges the funding support received from RADMA (Research and Development Management) used for conducting the empirical study. The second author acknowledges the support of the National Institute for Health Research Collaboration for Leadership in Applied Health Research and Care (NIHR CLAHRC) Greater Manchester. The views expressed are those of the authors and not necessarily those of the NHS, the NIHR or the Department of Health.

\section{References}

Akkerman, S. F. \& Bakker, A. (2011) Boundary crossing and boundary objects. Review of Educational Research, 81(2), 132-169.

Allen, J., James, A. D. \& Gamlen, P. (2007) Formal versus informal knowledge networks in R\&D: A case study using social network analysis. $R \& D$ Management, 37(3), 179-196. 
Anderson, P. (1999) Complexity theory and organization science. Organization Science, 10(3), 216-232.

Barrett, M., Oborn, E., Orlikowski, W. J. \& Yates, J. (2012) Reconfiguring boundary relations: Robotic innovations in pharmacy work. Organization Science, 23(5), 1448-1466.

Becker, W. \& Dietz, J. (2004) R\&D cooperation and innovation activities of firmsevidence for the German manufacturing industry. Research Policy, 33(2), 209223.

Bidault, F. \& Cummings, T. (1994) Innovating through alliances: Expectations and limitations. $R \& D$ Management, 24(1), 33-45.

Bogers, M. (2011) The open innovation paradox: knowledge sharing and protection in R\&D collaborations. European Journal of Innovation Management, 14(1), 93117.

Bromiley, P. \& Rau, D. (2014) Towards a practice-based view of strategy. Strategic Management Journal, 35(8), 1249-1256.

Brown, J. S. \& Duguid, P. (1991) Organizational learning and communities-of-practice: Toward a unified view of working, learning and innovation. Organization Science, 2(1), 40-57.

Burnes, B. (2005) Complexity theories and organizational change. International Journal of Management Reviews, 7(2), 73-90.

Carlile, P. R. (2002) A pragmatic view of knowledge and boundaries: Boundary objects in new product development. Organization Science, 13(4), 442-455.

Carlile, P. R. (2004) Transferring, translating, and transforming: An integrative framework for managing knowledge across boundaries. Organization Science, 15(5), 555-568.

Chesbrough, H. (2003) Open Innovation: The New Imperative for Creating and Profiting from Technology. Boston, MA: Harvard Business School Press.

Chesbrough, H. (2011) Bringing open innovation to services. MIT Sloan Management Review, 52(2), 85-90.

Cilliers, P. (2001) Boundaries, hierarchies and networks in complex systems. International Journal of Innovation Management, 5(2), 135-147.

Corradi, G., Gherardi, S. \& Verzelloni, L. (2010) Through the practice lens: Where is the bandwagon of practice-based studies heading? Management Learning, 41(3), 265-283.

Crossan, M. M. \& Apaydin, M. (2010) A multi-dimensional framework of organizational innovation: A systematic review of the literature. Journal of Management Studies, 47(6), 1154-1191.

Currie, G. \& White, L. (2012) Inter-professional barriers and knowledge brokering in an organizational context: The case of healthcare. Organization Studies, 33(10), 1333-1361.

Dodgson, M. (1992) The strategic management of R\&D collaboration. Technology Analysis \& Strategic Management, 4(3), 227-244.

Dougherty, D. (2004) Organizing practices in services: Capturing practice-based knowledge for innovation. Strategic Organization, 2(1), 35-64.

Dougherty, D. \& Dunne, D. D. (2011) Organizing ecologies of complex innovation. Organization Science, 22(5), 1214-1223.

Dyer, B. \& Song, X. M. (1998) Innovation strategy and sanctioned conflict: A new edge in innovation? Journal of Product Innovation Management, 15(6), 505-519.

Eisenhardt, K. M. (1989) Building theories from case study research. The Academy of Management Review, 14(4), 532-550. 
Evans, S. \& Scarbrough, H. (2014) Supporting knowledge translation through collaborative translational research initiatives: 'Bridging' versus 'blurring' boundary-spanning approaches in the UK CLAHRC initiative. Social Science \& Medicine, 106, 119-127.

Ferlie, E., Fitzgerald, L., Wood, M. \& Hawkins, C. (2005) The nonspread of innovations: The mediating role of professionals. The Academy of Management Journal, 48(1), 117-134.

Fernandez, R. M. \& Gould, R. V. (1994) A dilemma of state power: Brokerage and influence in the national health policy domain. American Journal of Sociology, 99(6), 1455-1491.

Fitzgerald, L., Ferlie, E., McGivern, G. \& Buchanan, D. (2013) Distributed leadership patterns and service improvement: Evidence and argument from English healthcare. The Leadership Quarterly, 24(1), 227-239.

Fox, N. J. (2011) Boundary objects, social meanings and the success of new technologies. Sociology, 45(1), 70-85.

Gulati, R., Lavie, D. \& Singh, H. (2009) The nature of partnering experience and the gains from alliances. Strategic Management Journal, 30(11), 1213-1233.

Guston, D. H. (1999) Stabilizing the boundary between US politics and science:: The rôle of the office of technology transfer as a boundary organization. Social Studies of Science, 29(1), 87-111.

Guston, D. H. (2001) Boundary organizations in environmental policy and science: An introduction. Science, Technology, and Human values, 26(4), 399-408.

Hoang, H. \& Rothaermel, F. T. (2005) The effect of general and partner-specific alliance experience on joint R\&D project performance. Academy of Management Journal, 48(2), 332-345.

Howells, J. (2006) Intermediation and the role of intermediaries in innovation. Research Policy, 35(5), 715-728.

Howells, J. (2008) New directions in R\&D: Current and prospective challenges. $R \& D$ Management, 38(3), 241-252.

Hsiao, R.-L., Tsai, D.-H. \& Lee, C.-F. (2012) Collaborative knowing: The adaptive nature of cross-boundary spanning. Journal of Management Studies, 49(3), 463491.

Huxham, C. \& Vangen, S. (2000a) Ambiguity, complexity and dynamics in the membership of collaboration. Human Relations, 53(6), 771-806.

Huxham, C. \& Vangen, S. (2000b) Leadership in the shaping and implementation of collaboration agendas: How things happen in a (not quite) joined-up world. The Academy of Management Journal, 43(6), 1159-1175.

Hyde, P. (2006) Managing across boundaries: Identity, differentiation and interaction. International Journal of Innovation and Learning, 3(4), 349-362.

Kimble, C., Grenier, C. \& Goglio-Primard, K. (2010) Innovation and knowledge sharing across professional boundaries: Political interplay between boundary objects and brokers. International Journal of Information Management, 30(5), 437-444.

Kislov, R. (2014) Boundary discontinuity in a constellation of interconnected practices. Public Administration, 92(2), 307-323.

Kislov, R., Walshe, K. \& Harvey, G. (2012) Managing boundaries in primary care service improvement: A developmental approach to communities of practice. Implementation Science, 7, 97. 
Kislov, R., Waterman, H., Harvey, G. \& Boaden, R. (2014) Rethinking capacity building for knowledge mobilisation: Developing multilevel capabilities in healthcare organisations. Implementation Science, 9, 166.

Klerkx, L. \& Leeuwis, C. (2008) Delegation of authority in research funding to networks: Experiences with a multiple goal boundary organization. Science and Public Policy, 35(3), 183-196.

Langley, A. (1999) Strategies for theorizing from process data. Academy of Management Review, 24(4), 691-710.

Levina, N. \& Vaast, E. (2005) The emergence of boundary spanning competence in practice: Implications for implementation and use of information systems. MIS Quarterly, 29(2), 335-363.

Li, D., Eden, L., Hitt, M. A. \& Ireland, R. D. (2008) Friends, acquaintances, or strangers? Partner selection in R\&D alliances. Academy of Management Journal, 51(2), 315-334.

Li, D., Eden, L., Hitt, M. A., Ireland, R. D. \& Garrett, R. P. (2012) Governance in multilateral R\&D alliances. Organization Science, 23(4), 1191-1210.

Miles, M. B. \& Huberman, A. M. (1994) Qualitative data analysis: An expanded sourcebook. Thousand Oaks, CA: Sage Publications.

Mintzberg, H. \& Waters, J. A. (1985) Of strategies, deliberate and emergent. Strategic Management Journal, 6(3), 257-272.

Mohr, J. \& Spekman, R. (1994) Characteristics of partnership success: Partnership attributes, communication behavior, and conflict resolution techniques. Strategic Management Journal, 15(2), 135-152.

Mørk, B. E., Aanestad, M., Hanseth, O. \& Grisot, M. (2008) Conflicting epistemic cultures and obstacles for learning across communities of practice. Knowledge and Process Management, 15(1), 12-23.

Mørk, B. E., Hoholm, T., Maaninen-Olsson, E. \& Aanestad, M. (2012) Changing practice through boundary organizing: A case from medical R\&D. Human Relations, 65(2), 263-288.

Morris, N. (2003) Academic researchers as 'agents' of science policy. Science and Public Policy, 30(5), 359-370.

Nadin, S. \& Cassell, C. (2004) Using data matrices. In: Cassell, C. \& Symon, G. (eds.) Essential Guide to Qualitative Methods in Organizational Research, pp. 271287. London: SAGE Publications.

Newell, S. (2004) Enhancing cross-project learning. Engineering Management Journal, $16(1), 12-20$.

O'Mahony, S. \& Bechky, B. A. (2008) Boundary organizations: Enabling collaboration among unexpected allies. Administrative Science Quarterly, 53(3), 422-459.

Oborn, E. \& Dawson, S. (2010) Knowledge and practice in multidisciplinary teams: Struggle, accommodation and privilege. Human Relations, 63(12), 1835-1857.

Organ, D. W. \& Greene, C. N. (1972) The boundary relevance of the project manager's job: Findings and implications for $\mathrm{R} \& \mathrm{D}$ management. $R \& D$ Management, 3(1), 7-11.

Oswick, C. \& Robertson, M. (2009) Boundary objects reconsidered: From bridges and anchors to barricades and mazes. Journal of Change Management, 9(2), 179193.

Oxley, J. E. \& Sampson, R. C. (2004) The scope and governance of international R\&D alliances. Strategic Management Journal, 25(8-9), 723-749. 
Perkmann, M. \& Walsh, K. (2007) University-industry relationships and open innovation: Towards a research agenda. International Journal of Management Reviews, 9(4), 259-280.

Roelofsen, A., Boon, W. P. C., Kloet, R. R. \& Broerse, J. E. W. (2011) Stakeholder interaction within research consortia on emerging technologies: Learning how and what? Research Policy, 40(3), 341-354.

Rycroft, R. W. \& Kash, D. E. (2002) Path dependence in the innovation of complex technologies. Technology Analysis \& Strategic Management, 14(1), 21-35.

Sakakibara, M. (2002) Formation of R\&D consortia: Industry and company effects. Strategic Management Journal, 23(11), 1033-1050.

Santos, F. M. \& Eisenhardt, K. M. (2005) Organizational boundaries and theories of organization. Organization Science, 16(5), 491-508.

Shohet, S. \& Prevezer, M. (1996) UK biotechnology: Institutional linkages, technology transfer and the role of intermediaries. $R \& D$ Management, 26(3), 283-298.

Slipersæter, S., Lepori, B. \& Dinges, M. (2007) Between policy and science: research councils' responsiveness in Austria, Norway and Switzerland. Science and Public Policy, 34(6), 401-415.

Swan, J., Scarbrough, H. \& Newell, S. (2010) Why don't (or do) organizations learn from projects? Management Learning, 41(3), 325-344.

Waring, J., Currie, G., Crompton, A. \& Bishop, S. (2013) An exploratory study of knowledge brokering in hospital settings: Facilitating knowledge sharing and learning for patient safety? Social Science \& Medicine, 98, 79-86.

Wenger, E. (1998) Communities of Practice: Learning, Meaning and Identity. Cambridge: Cambridge University Press.

Whittington, R. (2006) Completing the practice turn in strategy research. Organization Studies, 27(5), 613-634.

Yin, R. K. (2009) Case Study Research: Design and Methods (4th ed.). London: SAGE Publications. 
Table 1: Empirical cases.

\begin{tabular}{|l|l|l|l|}
\hline \multicolumn{1}{|c|}{ HOUSE } & \multicolumn{1}{|c|}{ ASTHMA } & \multicolumn{1}{|c|}{ FLIGHT } \\
\hline $\begin{array}{l}\text { Objective of an } \\
\text { R\& consortium }\end{array}$ & $\begin{array}{l}\text { Analysing the } \\
\text { thermal and } \\
\text { structural } \\
\text { characteristics of a } \\
\text { house made of } \\
\text { sustainable } \\
\text { materials }\end{array}$ & $\begin{array}{l}\text { Exploring the } \\
\text { genetic mechanisms } \\
\text { underpinning the } \\
\text { development of } \\
\text { asthma through } \\
\text { large-scale analyses } \\
\text { of patient data }\end{array}$ & $\begin{array}{l}\text { Developing a novel } \\
\text { coating technology } \\
\text { for aircraft titanium } \\
\text { bearings }\end{array}$ \\
\hline $\begin{array}{l}\text { Organisations } \\
\text { involved }\end{array}$ & $\begin{array}{l}\text { Six SMEs, a } \\
\text { university and a } \\
\text { research institute }\end{array}$ & $\begin{array}{l}\text { Two universities, } \\
\text { two research } \\
\text { institutes and five } \\
\text { pharmaceutical } \\
\text { companies }\end{array}$ & $\begin{array}{l}\text { An aircraft } \\
\text { manufacturer, a } \\
\text { company } \\
\text { specialised in } \\
\text { coating, a bearing } \\
\text { manufacturer and } \\
\text { the surface } \\
\text { engineering } \\
\text { department of a } \\
\text { university }\end{array}$ \\
\hline $\begin{array}{l}\text { Occupational } \\
\text { groups involved }\end{array}$ & $\begin{array}{l}\text { Structural engineers } \\
\text { (4 participants), } \\
\text { architects (3 } \\
\text { participants), } \\
\text { mechanical } \\
\text { engineers (2 } \\
\text { participants) and } \\
\text { farmers (1 } \\
\text { participant) }\end{array}$ & $\begin{array}{l}\text { Biology and } \\
\text { immunology (13), } \\
\text { medicine (4), } \\
\text { systems biology (4), } \\
\text { image processing } \\
\text { (1) }\end{array}$ & $\begin{array}{l}\text { Mechanical } \\
\text { engineers (4), } \\
\text { electrical engineers } \\
\text { (1) and surface } \\
\text { engineers (5) }\end{array}$ \\
\hline
\end{tabular}


Table 2: The sources of data.

\begin{tabular}{|c|c|c|c|c|}
\hline $\begin{array}{l}\mathrm{R} \& \mathrm{D} \\
\text { consortium }\end{array}$ & $\begin{array}{l}\text { Number of } \\
\text { interviews }\end{array}$ & $\begin{array}{l}\text { Number of } \\
\text { research } \\
\text { participants }\end{array}$ & $\begin{array}{l}\text { Documents that are } \\
\text { not publicly } \\
\text { available }\end{array}$ & Other sources \\
\hline HOUSE & 13 & 10 & $\begin{array}{ll}\text { - } & \text { The second-level } \\
\text { work plan } \\
\text { - } \\
\text { Research Project } \\
\text { Summary }\end{array}$ & $\begin{array}{ll} & \text { Published case } \\
\text { report } \\
\text { - } & \text { Organisation } \\
& \text { websites } \\
- & \text { TV shows } \\
- & \text { Co-authored } \\
& \text { publications }\end{array}$ \\
\hline ASTHMA & 22 & 22 & $\begin{array}{ll}\text { - } & \text { Detailed annual } \\
\text { project report } \\
\text { - } & \text { Meeting minutes } \\
\text { - } & \text { Online } \\
& \text { discussions }\end{array}$ & $\begin{array}{ll}\text { - } & \text { ASTHMA } \\
& \text { website } \\
- & \text { IMI website } \\
- & \text { Presentation } \\
& \text { videos } \\
- & \text { Co-authored } \\
& \text { publications } \\
- & \text { Observation at } \\
\text { annual } \\
\text { conference }\end{array}$ \\
\hline FLIGHT & 12 & 10 & $\begin{array}{ll}\text { - } & \text { Reports of } \\
& \text { quarterly } \\
\text { meetings } & \text { - } \\
\text { Presentations of } \\
\text { quarterly } \\
\text { meetings } \\
\text { - } & \text { Second-level } \\
\text { project plan } \\
\text { - } & \text { Project timelines } \\
& \text { and Gantt charts } \\
\text { - } & \text { Patents }\end{array}$ & $\begin{array}{ll}\text { - } & \text { Organisation } \\
& \text { websites } \\
- & \text { Published case } \\
& \text { report } \\
\text { - } & \text { Co-authored } \\
& \text { publications }\end{array}$ \\
\hline
\end{tabular}


Table 3: Deliberate and emergent aspects of boundary organising across the three cases.

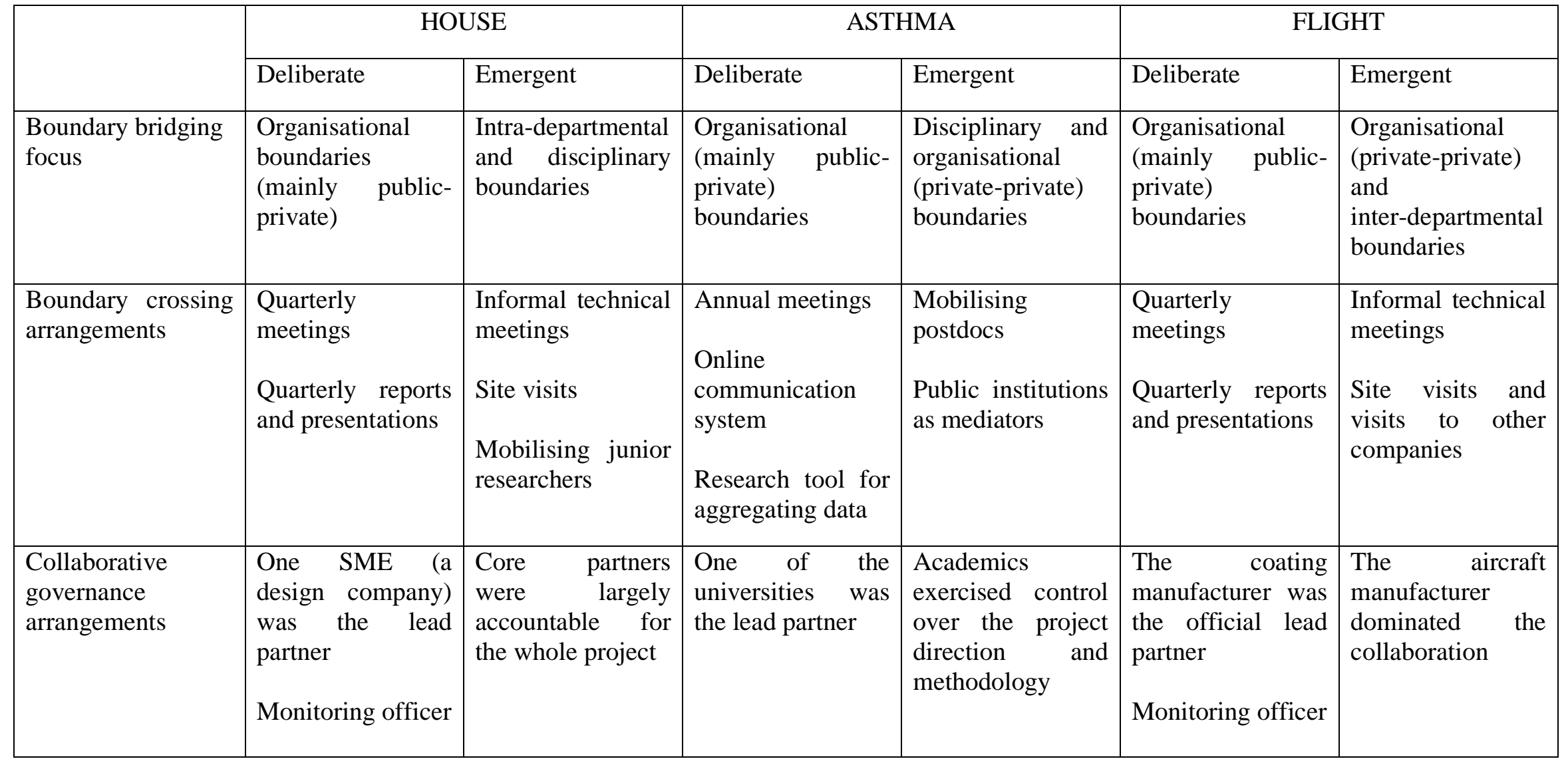

